Int. J. Electrochem. Sci., 12 (2017) $8006-8020$

\title{
Investigation on Electrochemical Corrosion of 304 Stainless Steel under Thin Electrolyte Layers Containing Chloride Ions
}

\author{
Xuequn Cheng, Hong Luo, Kui Xiao, Chaofang Dong*, \\ Corrosion and Protection Center, University of Science and Technology Beijing, Beijing 100083, \\ China \\ *E-mail: cfdong@ustb.edu.cn
}

doi: $10.20964 / 2017.09 .11$

Received: 31 May 2017 / Accepted: 29 June 2017 / Published: 13 August 2017

\begin{abstract}
The corrosion behaviour of 304 stainless steel (304 SS) under thin electrolyte layers containing chloride ions was studied by potentiodynamic polarization and electrochemical impedance spectroscopy (EIS). Data obtained from potentiodynamic polarization tests show that a reduction in the electrolyte layer thickness result in a negative shift of the pitting potential for 304 SS. Results that were collected from EIS analysis are also consistent with the potentiodynamic polarization curves, demonstrating a decrease in $R_{c t}$. This decrease indicates corrosion rate increase as the layer thickness decrease. Optical morphologies also reveal an increased amount of small corrosion pits under thinner electrolyte layers.
\end{abstract}

Keywords: A. 304 stainless steel; A. thin electrolyte layer; B. Potentiodynamic polarization; B. EIS; C. pitting corrosion

\section{FULL TEXT}

(C) 2017 The Authors. Published by ESG (www.electrochemsci.org). This article is an open access article distributed under the terms and conditions of the Creative Commons Attribution license (http://creativecommons.org/licenses/by/4.0/). 